\title{
Does early intervention reduce the number of elderly people with dementia admitted to institutions for long term care?
}

\author{
D W O'Connor, P A Pollitt, C P B Brook, B B Reiss, M Roth
}

\begin{abstract}
Objective-To test whether early diagnosis and practical help reduce the number of elderly people with dementia admitted to institutions.

Design-Controlled trial of effect of help from a multidisciplinary team on admission rates of people with dementia.

Setting-Seven general practices in Cambridge.

Subjects -2889 subjects aged 75 and over, of whom 159 were identified as having dementia with a two stage community survey. Eighty six subjects were referred for extra help if they or their supporters wished. The other 73 subjects had access to the usual services and served as controls.
\end{abstract}

Intervention-Subjects and families in the action group were offered a wide range of help, including financial benefits, physical aids, home helps, respite admissions, practical advice, and psychiatric assessments.

Main outcome measure-Permanent admission to long term care within two years after diagnosis.

Results-Early intervention did not affect admission rates in subjects who lived with supporters. By contrast, nine of the $14(64 \%)$ subjects with moderate or severe dementia living alone were admitted in the action group in the study's second year compared with only one of $13(8 \%)$ controls $(\mathbf{p}=\mathbf{0 . 0 0 4})$.

Conclusions-Some people with moderate or severe dementia who lived alone and were at serious risk may have been identified earlier by the resource team. Without the team these people would not have become known to the responsible authorities until families, neighbours, and wardens became unable to cope. The study was conducted during the team's formative period, however, and greater experience might have allowed some subjects to remain at home for longer.

Hughes Hall Project for Later Life, Cambridge CB1 2EW

$\mathrm{D}$ W O'Connor, $\mathrm{MD}$, research fellow

P A Pollitt, PHD, research fellow

C P B Brook, FRCPSYCH, consultant psychiatrist

B B Reiss, FRCGP, general practitioner

$M$ Roth, FRCPSYCH, emeritus professor of psychiatry

Correspondence to: Professor D W O'Connor, Heatherton Hospital, Heatherton, Victoria 3202, Australia.

\section{Introduction}

Two fifths of people with moderate and severe dementia identified in a recent British survey lived in residential homes or long stay hospital wards. ${ }^{1}$ Some deeply confused old people are nursed at home until they die by relatives, but this is sometimes impossible: an elderly spouse may have difficulty in coping with the unremitting burden of washing, dressing, and toileting; a son or daughter may have other commitments and, in a few cases, there may be no supporters. Even the best domiciliary services cannot, and should not, be expected to support all people with dementia at home indefinitely, ' but admissions could possibly be reduced if cognitive impairment were recognised at an earlier stage and if people with dementia and their families were provided with tailored practical and emotional support. ${ }^{3}$

People with dementia stand to benefit from current are now required to offer annual assessments to all their elderly patients, and local authorities will shortly assume responsibility for providing packages of care to help old people remain at home for as long as possible. Unfortunately, there is little evidence that programmes such as these are actually successful. Social workers in Cleveland, Ohio, provided practical, financial, and medical assistance to elderly women, most of whom were appreciably demented and lived alone, but a quarter of the 76 women were taken into care over the course of a year compared with $18 \%$ of the matched controls. ${ }^{4}$ Similarly, when paid helpers in Ipswich provided emotional and practical support, $59 \%$ of the 27 surviving experimental subjects were admitted to residential homes or psychiatric wards within a year compared with $18 \%$ of the 11 surviving controls. The results from a parallel study in London were inconclusive.'

Some success, however, was obtained in a Kent study ${ }^{6}$ Elderly people who were judged to be at risk of admission because of mental or physical infirmity were offered intensive practical help. The expenses incurred rarely exceeded two thirds of the cost of an admission to a local authority old people's home. Sixty nine per cent of the 74 subjects given help remained at home after one year compared with $34 \%$ of the 74 controls, and substantial differences persisted for as long as four years. ${ }^{6}$ These achievements have since been replicated in Gateshead.

Such conflicting outcomes probably stem from differences in the subjects' social, medical, and psychiatric characteristics and in the amount and type of help provided. Participants in all these studies were known already to welfare or medical agencies, and some may have been too severely impaired to remain at home for much longer. We tried to circumvent this difficulty by identifying dementia at an earlier stage than usual. Our approach was in keeping with the recommendations laid out in the white paper Caring for People. ${ }^{8}$ medical and social developments. General practitioners
Subjects and methods SCREENING AND DIAGNOSIS

Patients aged 75 and over on 1 April 1986 were taken from the age-sex registers of six Cambridge general practices, and a one in three sample of patients was taken from a seventh practice to make up the numbers required for the study. Patients were visited by trained lay interviewers, who administered a brief cognitive test, the mini-mental state examination'; those who scored 23 points or less out of a maximum of 30 points were assessed by psychiatrists. This score was chosen on the basis of previous reports that no patients with dementia scored above this level. ${ }^{9}$ One in three of respondents who scored 24 or 25 points were also assessed in detail because of our interest in mild dementia. 
Psychiatrists conducted a structured interview, the Cambridge examination for mental disorders in the elderly (CAMDEX), ${ }^{10}$ which takes between 60 and 90 minutes to complete and comprises a present state assessment, a medical and psychiatric history, detailed cognitive tests, and a brief physical examination. In addition, questions were put to informants (usually relatives) about changes in memory, intellect, behaviour, and competence in everyday tasks and about the duration and course of symptoms. Diagnostic criteria were virtually identical to those contained in the third revision of the American Psychiatric Association's diagnostic and statistical manual." Dementia was graded as mild, moderate, or severe by using the descriptive criteria listed in the box. The screening test and diagnostic interview were both administered reliably and diagnoses have been shown to be stable in all but a few cases. ${ }^{12-14}$

The diagnostic interview was conducted in surviving subjects one and two years later to check on progress and to confirm diagnoses. In addition, the supporters of subjects who were offered help were questioned at six monthly intervals about their experiences, difficulties, and use of services. Offers of help were repeated on each occasion so that supporters who felt able to manage by themselves at the start of the study could change their minds later. Supporters of control subjects were questioned only at the end of the study to check on use of services and admission of subjects into care during the study.

\section{EXPERIMENTAL DESIGN}

Elderly people with dementia living at home or in sheltered accommodation were divided into two groups. Those who lived north of the Cam (the area served by the resource team) were referred to the team if they or their supporters wished (the action group) whereas those who lived south of the river acted as controls and had access to the usual medical and social services. Both areas contained areas of relative affluence and deprivation and both were served by the same social service department and district health authority. The local provision of home helps, meals on wheels, and day care was similar to that in Britain as a whole..$^{15}$

The resource team, which was funded by the social service department, the health authority, and the research project, aimed at supporting mentally infirm old people and their families. It accepted referrals from all sources, although most came from the research project, general practitioners, and community nurses. Staffing levels varied throughout the study. For the first few months the team comprised a social worker and community psychiatric nurse, who spent much of their time forging contacts and devising interventions. For most of the study, however, the team comprised a secretary; two full time equivalent social workers; two full time equivalent community psychiatric nurses; and a part time occupational therapist, physiotherapist, and volunteer coordinator. A geriatrician and psychogeriatrician provided one or two sessions a week.

Referrals were assessed as quickly as possible, and cases were discussed at a weekly multidisciplinary meeting, when an appropriate key worker was appointed to oversee developments. If extra help was required it was provided either by the team or by outside agencies that maintained control over their own workers. The team provided personal contact, practical advice, family counselling, liaison with general practitioners and other agencies, relatives' support groups, social groups, a volunteer service, night sitters, and respite admissions.

\section{ANALYSIS}

Numbers in the experimental and control areas were roughly balanced but, within each group, subjects'

\section{Criteria for rating the severity of dementia}

Mild dementia-Difficulty in recalling recent information; limited or patchy disorientation in time and place; impaired problem solving ability, reasoning, and capacity to manage usual activities; diminished clarity of speech; defective knowledge of names of prominent figures; social façade and emotional responsiveness may well be retained but cognitive deficits are present on testing

Moderate dementia-Severely impaired reasoning, problem solving ability, and recall of recent events; disoriented in time and place; language unclear but not unintelligible; incapable of managing housework, shopping, or finances; needs help with dressing and other self care; may be occasionally incontinent; testing shows advanced deficits

Severe dementia-Incapable of recall, reasoning, or self care; almost invariably incontinent, apathetic, and inert; totally incapable of independent existence

circumstances varied considerably. For this reason results were stratified by using two preselected variables: dementia severity (mild $v$ moderate or severe dementia) and living arrangements (living alone $v$ living with others). ${ }^{16}$ Elderly people who declined referral or who died before this could be arranged were retained in the analysis on the grounds that similar losses would almost certainly have occurred in the control area had extra help been made available there.

Results for the first and second years are presented separately, partly because the team took several months to become fully established and partly because of changes in the subjects' circumstances. For example, a third of those who were mildly demented initially and who survived for 12 months were rated as moderately or severely demented one year later. Results for the second year were stratified by dementia severity and living arrangements at the time of the 12 month psychiatric reassessment. Continuously distributed variables were analysed by Mann-Whitney U tests and categorical variables were analysed by Pearson's $\chi^{2}$ tests.

\section{Results}

STUDY POPULATION

The mini-mental state examination was completed for 2616 of 2889 subjects; 207 refused, 52 could not be contacted, and 14 were too ill to participate. The study population, which comprised a third of local residents aged 75 and over, was representative of the index population in terms of age, sex, and type of accommodation. ${ }^{1}$ The response rate in the diagnostic phase was $81 \%(532 / 657) ; 82$ refused, 21 had died, nine could not be contacted, six spoke little or no English, and seven were missed for other reasons.

One hundred and sixty four people who lived at home or in sheltered accommodation were identified as having dementia, but five were judged to be cognitively intact or minimally demented one or two years later. This left 86 people who lived in the area served by the resource team and 73 who lived outside it. The action and control groups were adequately matched in terms of their social and psychiatric state at the time of diagnosis (table I), although subjects with mild dementia in the experimental group had slightly lower scores on the screening test and a smaller proportion received meals on wheels.

\section{INTERVENTION}

Fifty nine of the 86 subjects in the action group were referred to the resource team. Six died before a relative 


\begin{tabular}{|c|c|c|c|c|c|c|}
\hline & \multicolumn{2}{|c|}{ Mild dementia } & \multirow[b]{2}{*}{$\mathrm{p}$ Value } & \multicolumn{2}{|c|}{ Moderate or severe dementia } & \multirow[b]{2}{*}{$\mathrm{p}$ Value } \\
\hline & $\begin{array}{l}\text { Action } \\
(n=42)\end{array}$ & $\begin{array}{l}\text { Control } \\
(n=38)\end{array}$ & & $\begin{array}{l}\text { Action } \\
(n=44)\end{array}$ & $\begin{array}{l}\text { Control } \\
(\mathrm{n}=35)\end{array}$ & \\
\hline Age (years) & $85 \cdot 0(75-97)$ & $83 \cdot 5(77-94)$ & NS & $82 \cdot 5(75-101)$ & $84 \cdot 0(75-92)$ & NS \\
\hline Screening test score & $20 \cdot 0(0-24)$ & $21 \cdot 0(0-25)$ & $\mathrm{p}=0.028$ & $14 \cdot 5 \quad(0-23)$ & $15 \cdot 0(0-23)$ & NS \\
\hline Activities of daily living score & $7 \cdot 0(0-15)$ & $5 \cdot 5(0-14)$ & NS & $10 \cdot 0 \quad(1-18)$ & $9 \cdot 0 \quad(2-18)$ & NS \\
\hline Women & $27(64)$ & $25(66)$ & NS & $34(77)$ & $20(57)$ & NS \\
\hline \multicolumn{7}{|l|}{ Marital status: } \\
\hline Mąrried & $14(33)$ & $14(37)$ & NS & $21(48)$ & $12(34)$ & NS \\
\hline Widowed & $24(57)$ & $21(55)$ & & $21(48)$ & $20(57)$ & \\
\hline Other & $4(10)$ & $3(8)$ & & $2(5)$ & $3(9)$ & \\
\hline \multicolumn{7}{|l|}{ Social class': } \\
\hline I-III non-manual & $13(32)^{\star}$ & $13(34)$ & NS & $18(42)^{\star}$ & $8(24) \dagger$ & NS \\
\hline III manual-V & $28(68)$ & $24(63)$ & & $25(58)$ & $25(76)$ & \\
\hline \multicolumn{7}{|l|}{ Accommodation: } \\
\hline Non-sheltered & $32(76)$ & $32(84)$ & NS & $39(89)$ & $30(86)$ & NS \\
\hline Sheltered & $10(24)$ & $6(16)$ & & $5(11)$ & $5(14)$ & \\
\hline Lived alone & $20(48)$ & $19(50)$ & NS & $18(41)$ & $14(40)$ & NS \\
\hline Lived with other & $22(52)$ & $19(50)$ & & $26(59)$ & $21(60)$ & \\
\hline \multicolumn{7}{|l|}{ Local children: } \\
\hline None & $15(36)$ & $10(26)$ & NS & $15(34)$ & $18(51)$ & NS \\
\hline One or more & $27(64)$ & $28(74)$ & & $29(66)$ & $17(49)$ & \\
\hline \multicolumn{7}{|l|}{ Type of dementia: } \\
\hline Senile & $34(81)$ & $33(87)$ & NS & $35(80)$ & $23(66)$ & NS \\
\hline Vascular & $4(10)$ & $5(13)$ & & $7(16)$ & $10(29)$ & \\
\hline Mixed or other & $4(10)$ & & & $2(5)$ & $2(6)$ & \\
\hline \multicolumn{7}{|l|}{ Severity of dementia: } \\
\hline Moderate & & & & $38(86)$ & $29(83)$ & NS \\
\hline Severe & & & & $6(14)$ & $6(17)$ & \\
\hline \multicolumn{7}{|l|}{ Assistance: } \\
\hline Home help & $13(31)$ & $16(42)$ & NS & $18(41)$ & $16(47)^{\star}$ & NS \\
\hline Meals on wheels & $6(14)$ & $12(32)$ & $\mathrm{p}=0.064$ & $12(27)$ & $12(35)^{\star}$ & NS \\
\hline District nurse & $5(12)$ & $5(13)$ & NS & $14(32)$ & $12(35)^{\star}$ & NS \\
\hline Day centre & $1(2)$ & $4(11)$ & NS & $8(18)$ & $10(29)^{\star}$ & NS \\
\hline
\end{tabular}

${ }^{\star}$ Data missing on one subject.

†Data missing on two subjects

could be interviewed and four died shortly afterwards; two supporters refused to be interviewed (one was terminally ill), and 15 subjects or supporters declined the offer of referral (seven subjects had mild dementia and 11 lived with relatives). Those refusing referral denied having pressing difficulties, others had sufficient help from the social services or private employees, and some preferred to cope alone.

Subjects were referred to the team whenever they or their supporters chose. Five subjects had been referred by general practitioners or nurses before diagnosis, 34 were referred by the research project within six months after diagnosis, six 13-18 months after diagnosis, and four 19-23 months. The assistance was matched as closely as possible to individual needs. Three supporters were assessed by the team but declined further contact; some required only basic forms of help (for example, physical aids) whereas others received regular visits, emotional support, and practical assistance. Though much of the project's work could not be quantified, among the practical interventions provided or initiated by the team, home helps, day care, respite admissions, and psychogeriatric assessments figured prominently (table II). (At the end of the first year the role of home helps in Cambridge changed from performing basic household duties to providing assistance with personal care.) Twelve people received intensive support in the form of frequent visits over sustained periods, visits from home helps more than once a day, and regular respite admissions.

TABLE II -Subjects for whom services were initiated by resource team

\begin{tabular}{lc}
\hline Service & $\begin{array}{c}\text { No of } \\
\text { subjects } \\
(\mathbf{n}=59)\end{array}$ \\
\hline Home help & 22 \\
Day care & 18 \\
Respite admissions & 18 \\
Physical aids & 17 \\
Voluntary help & 15 \\
Psychiatric assessment & 15 \\
Financial benefits & 13 \\
Meals on wheels & 11 \\
District nurse & 6 \\
Chiropody & 6 \\
Night sitter & 4 \\
Relative support group & 4 \\
Physiotherapy & 2 \\
\hline
\end{tabular}
the second year, however, more pate in the action group were admitted than in the contro group, especially among those with moderate and severe dementia. This difference was not due to a group were admitted permanently to reside
TABLE III -Numbers (percentages) of subjects admitted to institutions within one and two years after diagnosis

\begin{tabular}{|c|c|c|c|}
\hline & $\begin{array}{l}\text { Action } \\
\text { group }\end{array}$ & $\begin{array}{l}\text { Control } \\
\text { group }\end{array}$ & $\mathrm{p}$ Value \\
\hline \multicolumn{4}{|c|}{ First year } \\
\hline No of subjects & 86 & 73 & \\
\hline \multicolumn{4}{|l|}{ Mild dementia: } \\
\hline Lived alone & $2 / 20(10)$ & $2 / 19(11)$ & NS \\
\hline Lived with others & $0 / 22$ & $1 / 19(5)$ & NS \\
\hline \multicolumn{4}{|c|}{ Moderate or severe dementia: } \\
\hline Lived alone & $4 / 18(22)$ & $5 / 14(36)$ & NS \\
\hline \multirow[t]{2}{*}{ Lived with others } & $4 / 26(15)$ & $2 / 21(10)$ & NS \\
\hline & Second year & & \\
\hline No of subjects & 58 & 47 & \\
\hline \multicolumn{4}{|l|}{ Mild dementia: } \\
\hline $\begin{array}{l}\text { Lived alone } \\
\text { L }\end{array}$ & $5 / 14(36)$ & $1 / 7 \quad(14)$ & NS \\
\hline Lived with others & $1 / 12(8)$ & $1 / 9$ (11) & NS \\
\hline \multicolumn{4}{|c|}{ Moderate or severe dementia: } \\
\hline Lived alone & $9 / 14(64)$ & $1 / 13(8)$ & $0 \cdot 004$ \\
\hline Lived with others & $4 / 18(22)$ & $3 / 18(17)$ & NS \\
\hline
\end{tabular}

greater degree of disability or disturbed behaviour within the action group, as $57 \%(8 / 14)$ of subjects with moderate or severe dementia in the action group who lived alone needed help to transfer, were doubly incontinent, had frequent falls, wandered, or had a history of accidents with gas or electricity compared with $53 \%(7 / 13)$ of controls.

Taking both years together, 29 subjects in the action group were admitted to institutions (of whom 26 had been referred to the team) compared with 16 controls, but not all of the admissions in the action group could be traced to the team as 13 of the 29 admissions resulted from transfers from acute hospital wards and three were initiated by families or wardens. Sixteen people were admitted directly to residential homes; five were admitted to residential homes through a hospital, seven went to long stay geriatric wards, and one to a long stay psychogeriatric ward. Within the control group, nine of the 16 admissions were to residential homes, five to long stay geriatric wards, and two to psychogeriatric wards. Thus the higher rate among subjects offered help was due to a greater number of admissions to old people's homes. It seems unlikely that there was a more generous provision of local authority beds in the experimental area as 18 of 
the 21 admissions to residential homes were to private homes, compared with four out of nine in the control area.

The reasons for admission were often complex. Among subjects offered help primary supporters died in three cases and two subjects were profoundly physically disabled, but other admissions were largely or solely caused by relatives' inability to cope with the effects of dementia. Acute admissions to hospital because of falls or infections played a part: although some subjects made full physical recoveries, their supporters felt unable to manage any longer and chose to withdraw. Similar factors played a part in the control group: three subjects were physically disabled because of stroke or Parkinson's disease and needed full nursing care, but the remainder were admitted largely or solely because of mental incapacity.

\section{Discussion}

We expected to find that families would be distressed by mild dementia in a spouse or parent and that early identification and practical help would forestall the development of damaging levels of burden. Some mildly impaired old people were physically frail and needed assistance with mobility aids, financial benefits, and day care, but most relatives saw mild dementia as a normal part of aging and some were puzzled by our interest. ${ }^{17}$ Team members commonly settled for occasional visits to check that all was well and, in retrospect, their efforts would have been better directed towards helping subjects and families in greater difficulties. Subjects with mild dementia in the action group who lived alone were more likely to be taken into care than control subjects in the study's second year, although the difference was not significant. Thirty subjects would be needed in each group to detect a difference of this size at a significance level of $p=0.05$, and so the meaning of our finding remains unclear. ${ }^{18}$

Relatives caring for people with moderate or severe dementia reported numerous problems, and many were under strain..$^{19}$ Most spouses and children living with parents with dementia were committed to persist in their task for as long as possible to such an extent that, when arrangements did break down, little could have been done to prevent this happening. Of those wholived with supporters, four of the seven appreciably demented subjects in the action group required full time nursing attention; one woman was terminally ill; the wife of one subject had died; and the husband of another was a chronic alcoholic and became incapable of caring for himself.

People with moderate or severe dementia in the action group who lived alone were more likely to be admitted to institutions. Several control subjects have since been admitted, which suggests that some of these admissions were simply brought forward. Without the resource team many people with dementia would not have been identified by the authorities until carers became unable to cope. The result was striking, none the less, and agrees with previous findings in Ohio and Ipswich. ${ }^{+5}$ All but four of these subjects had relatives living nearby, most of whom were genuinely concerned and gave what time they could to subjects's care. Many were desperate for extra help, and surprising numbers asked for their relative to be taken into care. The team worked in close conjunction with families, but if relatives insisted on admission little could be done to prevent this as effective domiciliary care requires the cooperation of families.

Dementia poses special difficulties: $35 \%$ of people with moderate or severe dementia in Cambridge could not be left alone for one hour, $55 \%$ had urinary incontinence, and $74 \%$ needed help with dressing. ${ }^{19}$ In addition, relationships between people with dementia and their carers fragment with the erosion of the sufferer's intellect and personality, and the task of caring becomes increasingly strained. ${ }^{20}$ It would be wrong to insist that all people with dementia be cared for at home until they die. Admission to a residential home that offers dignity, privacy, and pesonal attention is preferable in some instances, although this depends on the quality of the institutions available.

Our findings seem at first sight to contradict those in Kent, where provision of specially tailored help reduced the admission rates, but the Kent results are complex. ${ }^{6}$ The admission rates for physically or mentally frail old people in Kent in the action group who lived with relatives differed only slightly from those for controls $(10 \% v 13 \%)$, as in our study. By contrast, $13 \%$ and $25 \%$ of physically frail people were admitted in the action and control groups respectively after one year compared with $20 \%$ of mentally frail people admitted in the action group and $27 \%$ in the control group. ${ }^{6}$ The effect on admissions associated with physically frail people might also account for the recent report that screening general practice patients reduced the number of admissions to residential homes, although this was accompanied by an increase in admissions to hospital. ${ }^{21}$ Hospital admission may not be appropriate for physically fit people with dementia.

The results of studies of the needs of mentally frail old people suggest that special assistance might actually increase rather than decrease the numbers admitted to institutions, particularly for those who live alone. The Cambridge team, however, was evaluated in its infancy and its results might now be different. New services have to contend with the most intransigent cases when they are at least equipped to do so. In addition, team members now have a clearer perception of the merits and deficiencies of local residential homes and are more confident in dealing with disturbed old people and calming the sometimes excessive concerns of younger relatives. Even so, some people with dementia will continue to be admitted to residential homes and long stay hospital wards, and for some people moving to an environment that provides safety, security, and affection is actually preferable.

We thank the general practitioners, Cambridge health authority, Cambridge social services department, and members of the community resource team for their trust and cooperation; Dr John Hyde, Dr Jan Fellowes, Dr Nigel Miller, and Beryl Jones for help with diagnostic interviews; Irene Anderson, Sheila Abrams, Glynis Longstaff, and Margaret Guy for help with family interviews; and Dr Basi Herbertson and Sir David Wolfson for support and encouragement. The Hughes Hall Project for Later Life was funded by the Charles Wolfson Charitable Trust.

1 O'Connor DW, Pollitt PA, Hyde JB, et al. The prevalence of dementia a measured by the Cambridge mental disorders of the elderly examination. Acta Psychiatr Scand 1989;79:190-8.

2 Opit LJ. Domiciliary care for the elderly sick: economy or neglect? $B M \mathcal{J}$ 1977;i:30-3.

3 Godber C. Planning services for the elderly demented patient. Age Aging 1977;6:100-3.

4 Blenkner $M$. Bloom $M$, Nielsen $M$. A research and demonstration project of protective services. Social Casezvork 1971:52:483-99.

5 Askham J. Thompson C. Dementia and home care. London: Age Concern, 1990.

6 Challis D, Davies B. Case management in community care: an evaluated experiment in the home care of the elderly. Aldershot: Gower, 1986.

7 Challis D, Chessum R, Chesterman J, Luckett R, Traske K. Case managemen in social and health care. Canterbury: University of Kent Personal. Social Services Research Unit, 1990.

8 Secretaries of State for Health, Social Security, Wales, and Scotland. Caring for people. London: HMSO, 1989.

9 Folstein MF, Folstein SE, McHugh PR. Mini-mental state: a practica method for grading the cognitive state of patients for the clinician. F Psychiatr Res 1975;12:189-98.

10 Roth M. Tym E, Mountioy CQ, et al. CAMDEX: a standardised instrumen for the diagnosis of mental disorder in the elderly with special reference to the early detection of dementia. Br f Psychiatry 1986;149:698-709. 11 American Psychiatric Association. Diagnostic and statistical manual. 3rd ed, 120 O'Connor DW, Pollitt PA, Hyde JB, et al. The reliability and validity of the 
13 O'Connor DW, Pollitt PA, Hyde JB, Fellowes JF, Miller ND, Roth M. A follow-up study of dementia diagnosed in the community using the Cambridge mental disorders of the elderly examination. Acta Psychiar Cambridge mental

14 O'Connor DW, Pollitt PA, Brook CPB, Reiss BB. The validity of informant histories in a community study of dementia. International fournal of Geriatric Psychiatry 1989;4:203-8.

15 O'Connor DW, Pollitt PA, Brook CPB, Reiss BB. The distribution of services to demented elderly people living in the community. International goumal of Geriatric Pychiary $1989,4: 339$ in

16 Branch LG, Jette AM. A prospective study of long-term care and inștitution alization among the aged. Am F Public Health 1982;72:1373-9.
17 Boas JW, Haybittle JL, Fowler JF, Emery EW. The number of patients required in a clinical trial. Brf Radiol 1971;44:122-5.

8 Pollitt PA, O'Connor DW, Anderson I. Mild dementia: perceptions and problems. Ageing and Society 1989;9:261-75

19 O'Connor DW, Pollitt PA, Roth M, Brook CPB, Reiss BB. Problems reported by relatives in a community study of dementia. Br F Psychiatry 1990;156: $835-41$

20 Gilleard CJ. Living with dementia: community care for the elderly mentally infirm. Beckenham: Croom Helm, 1984.

21 Carpenter GI, Demopoulus GR. Screening the elderly in the community: controlled trial of dependency surveillance using a questionnaire administered by volunteers. BMF 1990;300:1253-6.

(Accepted 6 February 1991 )
Institute of Child Health, University of Bristol, Bristol BS2 8BJ

Karen Thorpe, PHD, research psychologist

Jean Golding, PHD, reader in child health

Rosemary Greenwood, MSC, research assistant

University of Aberdeen, Aberdeen

Ian MacGillivray, $\mathrm{MD}$ emeritus professor of obstetrics and gynaecology

Correspondence to: $\mathrm{Dr}$ Thorpe.

BMf 1991;302:875-8

\title{
Comparison of prevalence of depression in mothers of twins and mothers of singletons
}

\author{
Karen Thorpe, Jean Golding, Ian MacGillivray, Rosemary Greenwood
}

\begin{abstract}
Objective-To determine whether the apparent additional and exceptional stresses associated with bearing and parenting twins affect the emotional wellbeing of mothers.

Setting-Great Britain, 1970-5.

Design-Cohort study of 13135 children born between 4 April and 11 April 1970. Mothers of all children, both singletons and twins, were interviewed by health visitors (providing demographic data) and completed a self report measure of emotional wellbeing (the Rutter malaise inventory) when the child was 5 years of age. The malaise scores of mothers of twins were compared with those of all mothers of singletons and then with those of mothers categorised by the age spacing of their children (only one child, widely spaced, or closely spaced), taking account of maternal age, social class, and whether the study child had a disability, by using logistic regression.
\end{abstract}

Subjects-139 mothers of twins-122 pairs of twins and 17 twins whose cotwin had died-and 12573 controls, who were mothers of singletons.

Results - A significantly higher proportion of mothers of twins at 5 years had malaise scores indicative of depression than mothers of singletons at the same age. Mothers who had borne twins, one of whom had subsequently died, had the highest malaise scores and were three times more likely than mothers of singletons to experience depression. Both mothers of twin pairs and mothers of singletons closely spaced in age were at significantly higher risk of experiencing depression than mothers of children widely spaced in age or mothers of only one child $(p<0.0001)$. Odds ratios indicated that the risk of depression in mothers of twins was higher than that in mothers of closely spaced singletons.

Conclusion-Mothers of twins are more likely to experience depression. This suggests a relation between the additional and exceptional stresses that twins present and the mother's emotional wellbeing.

\section{Introduction}

The role of stressors in increasing vulnerability to depression is well recorded. Life events (for example, death, illness, and separation) and stressful life circumstances (such as poverty, unemployment, disability, and marital discord) have been shown to be associated with the onset and maintenance of depressive states. ${ }^{1.7}$ Among mothers, additionally, serious doubts about having the child, ${ }^{8}$ obstetric problems, ${ }^{9}$ and characteristics of the infant ${ }^{111}$ have been found to relate to the onset of depression.

Mothers of twins are particularly likely to be vulnerable to depression. The birth, pregnancy, and care of twins presents a series of life events and circumstances that are somewhat different from and typically more stressful than those experienced by mothers of singletons. Greater psychological conflict among mothers expecting a multiple birth has been documented. In addition to the feelings of ambivalence experienced by most mothers on confirmation of their pregnancy, ${ }^{12}$ these mothers experience conflicts relating to the extra financial, care, and health burdens of bearing twins. ${ }^{13-16}$ Though a sense of pride in being "exceptional" is often reported by these mothers, ambivalence, shock, depression, and anger on learning of a multiple pregnancy have been found to be universal. ${ }^{16-18}$

For mothers of twins the pregnancy may be more physically and emotionally stressful than a singleton pregnancy. Bodily discomfort is exacerbated, with greater feelings of heaviness occurring at an earlier stage in pregnancy. Increased risk of obstetric problems such as preterm labour, fetal growth retardation, and proteinuric pre-eclampsia are associated with multiple births, ${ }^{15}+9.22$ and as a consequence more frequent monitoring of the mother and fetus and obstetric interventions are likely. Though the impact of obstetric interventions on the emotional wellbeing of the mother has not been widely investigated, recent studies suggest that some interventions raise anxiety. ${ }^{23}$

Associated with the increased obstetric risk is a poorer outcome of twin pregnancies with regard to admission to special care, congenital abnormalities, and perinatal mortality. ${ }^{24}$ These are all great sources of stress that have long lasting effects on the parent. The death of one of the twins, in particular, has been found to have a long term impact. on the emotional wellbeing of the mother. ${ }^{19} 25$

Though there are few systematic studies, the financial and care burden associated with twins is commonly identified as a source of stress. In the early months there may be difficulties in coping with the often unsynchronised sleeping, feeding, and crying patterns of the two infants; fatigue and exhaustion are common. The logistics of taking two young children out often means that the mother remains at home, and this results in her isolation. ${ }^{26}{ }^{27}$ Feeling of guilt associated with the mother's inability to give adequate and equal attention to both children are also common. ${ }^{1315212829}$ These feelings are further exacerbated if there are other children who also demand the mother's attention and care. ${ }^{15}$ The incidence of child abuse has been found to be raised in families of twins, perhaps reflecting these stresses. ${ }^{1723}$ There is some suggestion, too, that the advent of twins may place a strain on the marital relationship. ${ }^{\text {is }}$ 